Published in final edited form as:

Cryogenics (Guildf). 2017 December ; 88: 147-155. doi:10.1016/j.cryogenics.2017.10.008.

\title{
Final Test Results for the Ground Operations Demonstration Unit for Liquid Hydrogen
}

\author{
W. U. Notardonato ${ }^{1}$, A.M. Swanger ${ }^{1}$, J. E. Fesmire ${ }^{1}$, K.M. Jumper ${ }^{1}$, W. L. Johnson ${ }^{2}$, T. M. \\ Tomsik $^{2}$ \\ ${ }^{1}$ NASA Kennedy Space Center, Cryogenics Test Laboratory, KSC, FL 32899 USA \\ ${ }^{2}$ NASA Glenn Research Center, Cleveland, OH USA
}

\begin{abstract}
Described herein is a comprehensive project-a large-scale test of an integrated refrigeration and storage system called the Ground Operations and Demonstration Unit for Liquid Hydrogen (GODU LH2), sponsored by the Advanced Exploration Systems Program and constructed at Kennedy Space Center. A commercial cryogenic refrigerator interfaced with a 125,000 liter liquid hydrogen tank and auxiliary systems in a manner that enabled control of the propellant state by extracting heat via a closed loop Brayton cycle refrigerator coupled to a novel internal heat exchanger. Three primary objectives were demonstrating zero-loss storage and transfer, gaseous liquefaction, and propellant densification. Testing was performed at three different liquid hydrogen fill-levels. Data were collected on tank pressure, internal tank temperature profiles, mass flow in and out of the system, and refrigeration system performance. All test objectives were successfully achieved during approximately two years of testing. A summary of the final results is presented in this paper.
\end{abstract}

\section{INTRODUCTION}

Recognizing the need for more capable and efficient cryogenic systems, NASA's Advanced Exploration Systems (AES) Program funded the development of the Ground Operations Demonstration Unit for Liquid Hydrogen $(\mathrm{GODU} \mathrm{LH} 2)$ in 2012. The GODU $\mathrm{LH}_{2}$ project is a relevant-scale prototype of an advanced $\mathrm{LH}_{2}$ system using Integrated Refrigeration and Storage (IRAS) technology to enable new types of operations not previously possible at the launch pads. IRAS couples state-of-the-art reverse-Brayton-cycle cryogenic refrigerators with liquid storage dewars using a submerged cold heat exchanger to remove energy directly from the fluid. If the refrigeration capacity matches the heat leak, a range of zero boiloff (ZBO) operations is possible. If the refrigerator capacity exceeds the heat leak, the liquid can be conditioned or densified, or gaseous hydrogen can be introduced to be liquefied. Small scale demonstrations of the IRAS technology were successfully completed with liquid hydrogen in 2005 [1] at the Florida Solar Energy Center and later with liquid oxygen at the Kennedy Space Center in 2009 [2]. The GODU $\mathrm{LH}_{2}$ project had three primary demonstration objectives for using IRAS on a relevant scale: (1) zero-loss storage and transfer of $\mathrm{LH}_{2}$, (2) densification of $\mathrm{LH}_{2}$, and (3) liquefaction of gaseous hydrogen $\left(\mathrm{GH}_{2}\right)$. Design and construction took three years between 2012 and 2014, and 19 months of testing was completed between March 2015 and September 2016. A high level summary of all the 
test results are presented here. Additional details of zero boil off tests and densification tests done during the GODU LH2 testing are available in other published papers $[3,4]$.

\section{GROUND OPERATIONS DEMONSTRATION UNIT FOR LIQUID HYDROGEN}

The functional diagram of the GODU $\mathrm{LH}_{2}$ system is given in Figure 1. The GODU $\mathrm{LH}_{2}$ system uses a $125 \mathrm{~m}^{3}$ vacuum-jacketed (VJ) IRAS tank with multilayer insulation as the primary storage vessel. This tank was previously used on Launch Complex 41 for the TitanCentaur Program. Pretest estimates of the tank heat leak from analysis and past operational data were approximately $300 \mathrm{~W}$. The IRAS tank is instrumented to record tank pressure and liquid and vapor temperatures. Three temperature rakes with $\mathrm{Si}-410$ silicon diodes accurate to $\pm 0.1 \mathrm{~K}$ are installed and located to provide vertical, longitudinal, and radial temperature gradients. The forward and aft rakes include arms to measure temperatures near the wall away from the centerline, whereas the center rake has only centerline diodes for better vertical resolution. The inner tank was modified with stiffening rings to allow for subatmospheric operation. The tank has redundant transducers for monitoring tank pressure. There are two vent systems, a $15 \mathrm{~cm}$ stack sized for high flow venting and emergency relief and a smaller $2.5 \mathrm{~cm}$ stack sized for the normal evaporation rate with a mass flow meter to monitor the flow rate during venting. Inside the IRAS tank is a cold heat exchanger (CHX), using gaseous helium which is connected to a cryogenic refrigerator. The CHX consists of $2.5 \mathrm{~cm}$ (1 in) tubular stainless-steel supply and return headers located at the $25 \%$ and $75 \%$ fill levels and connected by 40 parallel $0.6 \mathrm{~cm}(1 / 4 \mathrm{in})$ tubes that make up the bulk of the CHX surface area of approximately $83.6 \mathrm{~m}^{2}\left(900 \mathrm{ft}^{2}\right)$. Two of these tubes are instrumented with diodes to record helium inlet and outlet temperatures. The CHX is supplied with cold gaseous helium (GHe) from a Linde LR1620 refrigerator and RSX compressor at approximately $22 \mathrm{~g} / \mathrm{s}$. This system uses a reverse Brayton cycle with piston expansion engine and includes provisions for liquid nitrogen $\left(\mathrm{LN}_{2}\right)$ precooling. The refrigerator has a rated capacity of $390 \mathrm{~W}$ at $20 \mathrm{~K}$ without $\mathrm{LN}_{2}$ precooling and up to $880 \mathrm{~W}$ at $20 \mathrm{~K}$ with $\mathrm{LN}_{2}$ precooling. The refrigerator has independent command and control and instrumentation, notably for expander speed and cold helium supply and return temperature. A separate command and control system developed by NASA is also used for controlling refrigerator capacity based on IRAS tank pressure during some phases of testing. The RSX compressor is cooled by a separate $96 \mathrm{~kW}$ circulating water chiller at $292 \mathrm{~K}$ and includes systems for oil separation and gas management. The entire refrigeration system is containerized to allow for transportation to other test facilities, and this container has an integrated purge blower to keep the container at a slightly positive pressure to allow for operation in Class 1 Division 2 locations. Details of the refrigeration system, the IRAS tank, and the test plan have been published previously $[5,6]$.

\section{TEST PLAN}

The GODU $\mathrm{LH}_{2}$ test matrix includes testing of each of the primary objectives at three different fill levels-33\%, 67\%, and 100\%—with one delivered tanker of $\mathrm{LH}_{2}$ filling 
roughly $1 / 3$ of the tank. Additional boil off testing occurred at each fill level to characterize the tank heat leak as a function of liquid level.

The zero-loss storage and transfer objective consisted of multiple tests split between ZBO tests storage tests and zero-loss chilldown and tanker offload transfer tests. The ZBO storage tests were performed at each liquid level using three different control methods: helium supply temperature control, IRAS tank pressure control, and on/off duty cycling. Temperature control tests used Linde software to control the helium refrigerant supply temperature to the tank. Pressure control tests used KSC developed software to control the refrigeration power based on tank pressure response. Both these tests used internal heaters in the refrigerator to vary the helium temperature as needed, thereby introducing heat into the system to allow for continuous control. The duty cycling tests did not provide for continuous control, instead refrigeration was supplied in batch processes at full power. None of the ZBO storage tests required LN2 precooling. For the zero-loss-transfer objective, all tanker supply operations were performed with no venting losses, saving roughly $13 \%$ more of the delivered $\mathrm{LH}_{2}$ quantity than typical KSC practices. After each no loss tanker offload was complete, a short boil off test was completed to characterize the tank heat leak at that fill level. The initial cooldown of the tank was also done using the refrigerator to cool the $\mathrm{GH}_{2}$ in the tank to the normal boiling point (NBP). These zero-loss transfer tests typically used LN2 precooling to maximize refrigerator capacity and minimize required test time.

Densification tests were also conducted at each of the three liquid levels. During each densification test, all the tank liquid and vent valves are closed. The refrigerator is run at full power mode with $\mathrm{LN}_{2}$ precooling active. During densification operations, the IRAS tank pressure and liquid temperature decrease as long as the refrigerator capacity is greater than the tank heat leak. No helium gas pressure is applied to the ullage, and the tank pressure goes below atmospheric pressure. When the IRAS tank reaches the NBP, a low-pressure helium gas purge is applied to the stem seals and backside of all isolation valves and around the perimeter of all the flanges to prevent the intrusion of atmospheric air in the event of a leak. Eventually the system reaches an equilibrium temperature where the cryocooler refrigeration power equals the ambient heat load on the tank and refrigeration system. The pretest estimated minimum temperature for the system was $15 \mathrm{~K}$. Data are collected on heat exchanger and refrigerator performance and on the response of the liquid and vapor in the tank

Liquefaction testing was performed when the tank was at the $0 \%, 33 \%$ and $67 \%$ fill levels. There was no need to perform this test when the tank was $100 \%$ full. During liquefaction testing, the refrigerator is operated at full power and a mass flow controller introduces gaseous hydrogen into the tank at a rate that maintains constant pressure. During the system build phase, budget compromises forced the elimination of several key components from the liquefaction system. A liquid nitrogen pre-cooler with an integrated ortho-para conversion bed was eliminated from the design, making the system thermodynamically inefficient at liquefying hydrogen. Testing was conducted anyway, but due to the decreased importance of this objective in the near term, the tests were not as rigorous and repeatable as the other testing. 


\section{TEST RESULTS}

The Test Readiness Review for the GODU LH2 testing was completed in February 2015. At that time the IRAS tank had approximately $15 \mathrm{~m}^{3}$ (4000 gallons) of liquid nitrogen stored, and several weeks were needed to drain and purge all the nitrogen out of the system. Once the hydrogen concentration in the tank reached $99.5 \%$, the refrigerator was turned on. By this time the tank temperatures had increased back to near $300 \mathrm{~K}$ and any tank precooling from the LN2 cold shock was lost. The refrigerator was turned on and cooling to the tank was initiated in early April 2015. After several weeks the tank had reached $20 \mathrm{~K}$ and the first tanker offload was completed. Various ZBO tests were performed over the next several months as the operators gained experience in the system behavior and control PID loops were tuned. Numerous issues with refrigerator operations including helium leaks, valve adjustments, water chiller cooling and oil leaks at the compressor electrical feedthrus caused many delays and test interruptions during this time. Ultimately the oil leaks required reservicing the compressor with oil, and using an outdated procedure operators accidentally caused the compressor oil separation system to be overloaded. This led to contamination in the cold box and the refrigerator was out of commission from early October 2015 until March 2016. The original load of liquid hydrogen was lost during this time and testing was re-started in April 2016 with another tanker offload to refill the tank to the 33\% fill level. From this point the timeline was compressed, and the majority of the test results were obtained between this offload and October 2016, when the project was completed. Figure 2 below shows the tank pressure and liquid level during this timeline, and Table 1 gives the start and end dates of each individual test. Details on each of these tests are presented next.

\subsection{Zero-loss Storage and Transfer}

4.1.1 Zero-loss Chilldown - -By running the refrigeration system with $\mathrm{GH} 2$ in the IRAS tank, a zero-loss chill down was achieved. A plot of IRAS tank center rake temperatures and tank pressure over this time is shown in Figure 3. Over 920 hours, tank temperatures were reduced from approximately $290 \mathrm{~K}$ to approximately $21 \mathrm{~K}$, with the tank pressure dropping from $345 \mathrm{kPa}$ (50 psia) to $103 \mathrm{kPa}$ (15 psia), all while adding $109 \mathrm{~kg}$ of gaseous hydrogen. The hydrogen was added in batch processes and can be easily seen in the figure as spikes on the temperature and pressure plots. The refrigerator was running at full power during this operation with LN2 precooling active. A typical ground liquid hydrogen tank chill down from ambient temperature results in significant product losses. This is a new operational capability in large scale LH2 systems. On Earth this allows for more economical and safe system commissioning. But in space, the benefit is magnified by the cost of delivering the propellant, whether by resupply or from ISRU processes.

4.1.2 Zero-loss Tanker Offload - -Three zero-loss tanker offloads were performed. The initial offload took the tank from 0-33\% full and was the conclusion of a zero-loss chilldown and fill process from a hot tank to a cold tank with no product losses. The offload from 33-67\% was achieved with little difficulty, removing all the added energy in the system in less than 80 hours. The final tanker offload from $67 \%$ to $100 \%$ technically wasn't zero-loss, because the full trycock was opened near the end of the process to verify the final full liquid level. Data indicated the IRAS tank pressure increase was not to the point that the 
vent valve needed to be opened. In the future, addition of a wet/dry sensor at the full trycock level would eliminate the need for that minimal venting during the process of topping off the tank.

Figure 4 shows the system pressure response after each tanker offload. An initial pressure spike is followed by a rapid depressurization while the refrigerator works to de-stratify the tank and bring the ullage to saturated conditions. This is followed by a longer period when the refrigerator works to remove the energy from the bulk liquid. The initial tanker offload has the highest pressure spike due to the semi-warm tank, and details of that offload are shown in Figure 5. For that test, the time required to remove the heat and get the tank back to near atmospheric pressure is extended due to the refrigerator not being started until the next day. The steady $\mathrm{dP} / \mathrm{dt}$ for the pressure reduction is approximately $-1.7 \mathrm{kPa} / \mathrm{hr}(-0.25$ $\mathrm{psi} / \mathrm{hr}$ ) during the time with LN2 precooling and $-0.35 \mathrm{kPa} / \mathrm{hr}(-0.05 \mathrm{psi} / \mathrm{hr})$ without LN2 precooling. The second tanker offload was the easiest, with pressure rising to only $172 \mathrm{kPa}$ ( $25 \mathrm{psia}$ ). The time required to remove the energy was only 80 hours and the $\mathrm{dP} / \mathrm{dt}$ was $-0.76 \mathrm{kPa} / \mathrm{hr}(-0.11 \mathrm{psi} / \mathrm{hr})$ with LN2 precooling. The final offload had a moderate pressure spike to $234 \mathrm{kPa}$ ( $34 \mathrm{psia}$ ) before the full trycoock valve was opened. The required cooling time was the longest of the three, taking 200 hours to remove all the heat. This test was done using the refrigerator without LN2 precooling, giving a dP/dt of just $-0.2 \mathrm{kPa} / \mathrm{hr}(-0.03 \mathrm{psi} /$ hr).

4.1.3 Zero Boil Off - Pressure Control-The GODU LH2 system was built with an ability to control the refrigeration power delivered using the tank pressure transducer as the feedback mechanism. The control software was written to use PT1 as the control point, and all results in this section are referenced to PT1. To demonstrate full control of the tank pressure with the GODU-LH2 software, it was desirable to test the response of the system when a set-point is chosen at both higher and lower values than the tank pressure at that time - to converge to the desired pressure from "above" and "below." From above, the control logic allows the refrigerator to run at maximum capacity to drop the pressure as fast as possible and then introduce heat until the refrigerator lift balances the tank heat leak. Whereas, from below, the software introduces excessive heat into the tank to drive the pressure up to the set-point. The standard ZBO-PC test sequence was to set the control pressure to 18.0 psia, wait at least 24 hours after stabilization, then decrease the control pressure to 17.5 psia, wait for at least 24 hours after stabilization, then increase the control pressure to 18.5 psia, stabilize, and finally decrease the control pressure to 16.5 psia. Figure 6 shows a typical ZBO pressure control test at $33 \%$ fill level. The ZBO testing using tank pressure as the control variable was completely successful. Not only did the system show the ability to maintain the liquid hydrogen as a liquid with no losses for an indefinite time period, it demonstrated the ability to control the propellant to any storage condition desired. Testing at the three different liquid levels showed excellent controllability, and the only difference between tests was the amount of time required to reach steady state after changing from one set point to the next. The pressure response is faster than the temperature response, but eventually the liquid temperatures reach a steady state as well. 
4.1.4 Zero Boil Off - Temperature Control-The second method of zero boil off control is referred to as temperature control. The Linde refrigerator was supplied with a built in capability to control the supply temperature of the helium. More temperature control testing was conducted at the $33 \%$ fill level than the other fill levels. Temperature control testing with set points of $20 \mathrm{~K}, 19 \mathrm{~K}, 18 \mathrm{~K} 17 \mathrm{~K}$ and $16 \mathrm{~K}$ were all successfully completed during this time period as there was no hydrogen venting. The response time of the set point variable was very fast, reaching the prescribed helium temperature via the internal heater in a matter of minutes. Complete pressure and temperature stabilization of the liquid hydrogen took a much longer time depending on how close the eventual equilibrium point was to the initial conditions. All these tests took a long time to stabilize, and so for later fill levels of $67 \%$ and $100 \%$, testing was only conducted at $18 \mathrm{~K}$ for comparison purposes. The ZBO testing using temperature control of the helium supply met the test objectives. The system demonstrated the ability to maintain the LH2 in a liquid state indefinitely without venting. However, achieving a steady state condition was elusive as the fast helium temperature response time did not create an equally fast hydrogen storage response time.

4.1.5 Zero Boil Off - Duty Cycle-Numerous zero boil off tests were conducted, both intentionally and unintentionally, in a manner where the refrigerator cycled off and then on. This was referred to a duty cycling. Of these numerous tests, one representative test was chosen at each liquid level to be presented in detail. Figure 7 shows the tank pressure and center rake temperatures over time during the $33 \%$ fill level testing. These operations consisted of a period of time while the tank is self pressurizing and the ullage temperatures are stratifying, followed by a period when the refrigerator is operating and the tank temperatures and pressures are decreasing. The depressurization rate is typically fast at the start while the ullage temperatures collapse to an isothermal state, followed by a period where the depressurization rate slows as energy is removed from the bulk liquid. These tests were used to measure pressurization and depressurization rates, duty cycle ratios, and compare fluid behavior between the different liquid levels. Overall, ZBO Duty Cycle operations were accomplished with great success. This demonstrates the ability of the IRAS system to remove the energy accumulated during the off cycle with a refrigeration on a cycle of roughly the same time period. There was zero vent loss at every test. Temperatures and pressures were not steady during the test period by definition of being on a cycle, but ending temperatures and pressures matched the conditions at the start of the cycle.

\subsection{Densification}

A primary motivation for the GODU LH2 testing was to demonstrate the ability to cool the liquid hydrogen below the normal boiling point, a process referred to a propellant densification. A comparison of the densification timelines for the different liquid levels is shown in Figure 8. As expected, the time required to change the storage state is directly proportional to the mass in the tank. The $33 \%$ fill test, corresponding to roughly $4080 \mathrm{~kg}$ of LH2, needed just 107 hours to densify to a saturated pressure of $24 \mathrm{kPa}$ (3.5 psia), whereas the $67 \%$ fill test took 181 hours to densify to the same conditions, and the $100 \%$ fill test, with $8680 \mathrm{~kg}$ of LH2, took 298 hours. When the tank reaches the NBP, the $33 \%$ full tank is depressurizing at $-1 \mathrm{kPa} / \mathrm{hr}(-0.15 \mathrm{psi} / \mathrm{hr})$, compared to $-0.69 \mathrm{kPa} / \mathrm{hr}(-0.10 \mathrm{psi} / \mathrm{hr})$ for the $67 \%$ full tank and just $-0.34 \mathrm{kPa} / \mathrm{hr}(-0.05 \mathrm{psi} / \mathrm{hr})$ for the $100 \%$ full tank. At the $33 \%$ and 
$67 \%$ fill levels, the data suggest that significant amounts of slush hydrogen were produced as LH2 temperatures were observed to stabilize and then drop below the triple point (TP) temperature of $13.8 \mathrm{~K}$. In particular, details of the 33\% densification test are shown in Figure 9. This shows the tank center rake temperatures and tank pressure during the period the tank was subatmospheric, designated as T- 0 , and the point when the refrigerator was turned off. The NBP and TP are shown for reference. In this test, TT3 and TT4 are liquid temperatures and the others are in the ullage. The liquid temperatures decrease until they stabilize below the TP. At this point a liquid-solid phase change is occurring and slush hydrogen is being produced. Data analysis of the tank heat leak and refrigerator capacity during this period allow for an estimate of the quantity of solid being produced, and preliminary estimates show a solid mass fraction of approximately $25 \%$. After a period of time, these liquid temperatures again begin to decrease in temperature, below the TP, eventually reaching a minimum temperature of $12.8 \mathrm{~K}$. This behavior remains somewhat unexplained as there was insufficient instrumentation in the system to allow for full understanding of this period of time. Possible explanations for this behavior are the ultra pure hydrogen forms supercooled fluid in the absence of solid nucleation sites, or more likely the system is in a nonhomogenous state and some gaseous helium in the ullage is depressing the TP to below that of a pure substance.

All three of the densification tests successfully met the pretest prediction of $15 \mathrm{~K}$ bulk liquid temperatures. The first two tests at the lower liquid levels reached the TP, and slush hydrogen was produced. The final test was progressing toward the TP, but testing was terminated due to the end of the project life at the end of fiscal year 2016. This new capability is now available to further develop densified-propellant technology. Because the system was designed to be transportable, this new capability can be used at suitable engine test stands to provide densified hydrogen down to slush conditions for qualification testing. NASA is currently looking for interested partners to work in helping develop this technology.

\subsection{Liquefaction}

The third primary test objective was to demonstrate liquefaction of gaseous hydrogen using IRAS. The intent at the start of the project was to use GH2 from a tube trailer and run it thru a liquid nitrogen pre-cooler with an integrated ortho-para conversion bed to create equilibrium hydrogen at $78 \mathrm{~K}$. The refrigerator would operate at full power and a steady controlled rate of $\mathrm{GH} 2$ would flow into the tank while maintaining isobaric conditions. Project funding was cut in 2013 due to sequestration and other issues, and this objective was de-emphasized in favor of the ZBO and densification efforts. However, liquefaction was still achieved at each fill level, but the methods varied between each level. Liquefaction testing at the $0 \%$ fill level was accomplished during the chill down test, as gaseous hydrogen was introduced into the tank in several batch processes as the tank pressure decreased during cooling (Figure 3). The only continuous liquefaction test was performed at the $33 \%$ fill level, as the refrigerator was turned on at full power and hydrogen was introduced into the tank via a mass flow controller. The MFC regulated the hydrogen gas flow to maintain constant pressure in the tank during the liquefaction process. Figure 10 below shows the tank pressure, liquid level, and hydrogen mass flow rate during this test. Finally at the $67 \%$ fill 
level, liquefaction was achieved by a batch process of hydrogen flow while the tank was at subatmospheric conditions raising the tank pressure back to $103 \mathrm{kPa}$ (15 psia). In all, over $200 \mathrm{~kg}$ of hydrogen gas was liquefied during this testing, and future plans call for more steady liquefaction tests with pre-cooling and ortho-para conversion to better characterize the system behavior during this type of operation.

\section{CONCLUSION}

The GODU LH2 system has completed the initial round of functional tests using an Integrated Refrigeration and Storage method to remove heat from a cryogenic storage system. The system behavior depends on the refrigerator capacity compared to the heat leak of the tank. These tests have successfully demonstrated the three primary objectives: zeroloss storage and transfer, propellant densification, and hydrogen liquefaction. A zero-loss chilldown and three zero-loss tanker offloads successfully proved the capability to perform zero-loss cryogenic transfers. Three different zero boil off storage methods were tested at various fill levels to show the system capability for indefinite zero boil off storage. Most promising is the $\mathrm{ZBO}$ method using tank pressure as the control variable, as the system demonstrated the ability to control the liquid to essentially any point along the saturation line. This testing also demonstrated the ability to reliably produce large quantities of densified hydrogen down to the triple point.

\section{REFERENCES}

1. Notardonato WU, Baik JH, and McIntosh GE, "Operational Testing of Densified Hydrogen Using G-M Refrigeration”, Advances in Cryogenic Engineering, Vol. 49, American Institute of Physics, New York, 2004

2. Notardonato WU, Johnson WL, Oliveira J, and Jumper K; "Experimental Results of Integrated Refrigeration and Storage System Testing" Advances in Cryogenic Engineering, Vol. 57, American Institute of Physics, New York, 2012

3. Notardonato WU, Swanger AM, Fesmire JE, Jumper KM, Johnson WL, and Tomsik TM; "Zero Boil-Off Methods for Large Scale Liquid Hydrogen Tanks using Integrated Refrigeration and Storage"; Advances in Cryogenic Engineering, Vol 61, American Institute of Physics, New York, 2016

4. Notardonato WU, Swanger AM, Fesmire JE, Jumper KM, Johnson WL, and Tomsik TM; "Large Scale Production of Densified Hydrogen to the Triple Point and Below"; Advances in Cryogenic Engineering, Vol 61, American Institute of Physics, New York, 2016

5. Swanger AM, Notardonato WU, and Jumper K, “ASME Section VIII Recertification of a 33,000 Gallon Vacuum Jacketed LH2 Storage Vessel for Densified Hydrogen Testing at NASA Kennedy Space Center," PVP2015-45625, Proceedings of the ASME 2015 Pressure Vessels \& Piping Conference, July 19-23, 2015, Boston, Massachusetts, USA

6. Fesmire JE, Tomsik TM, Bonner T, Oliveira JM, Conyers HJ, Johnson WL, and Notardonato WU, "Integrated heat exchanger design for a cryogenic storage tank", AIP Conference Proceedings 1573, 1365 (2014); doi: 10.1063/1.4860865 


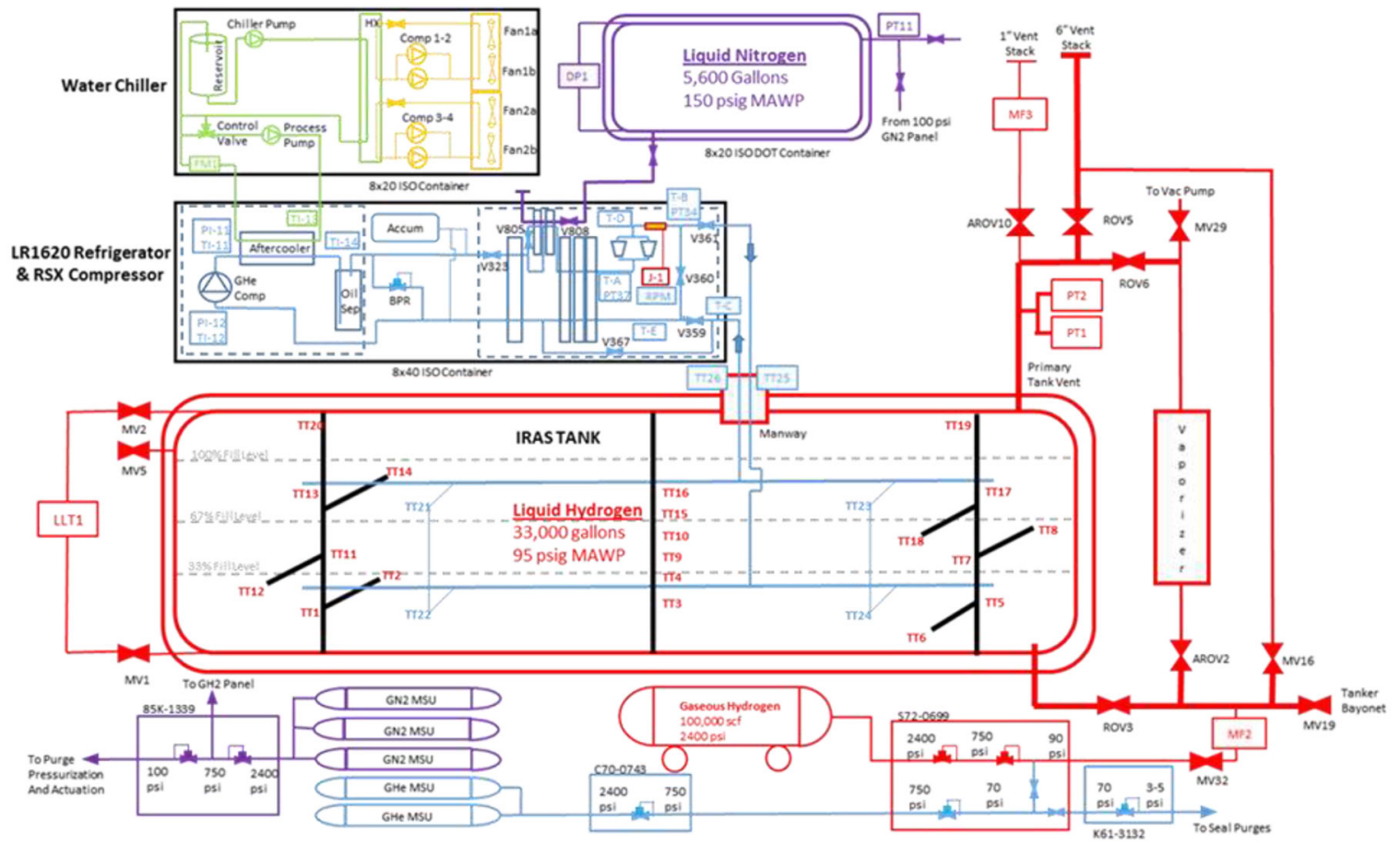

Figure 1.

GODU LH2 functional diagram 


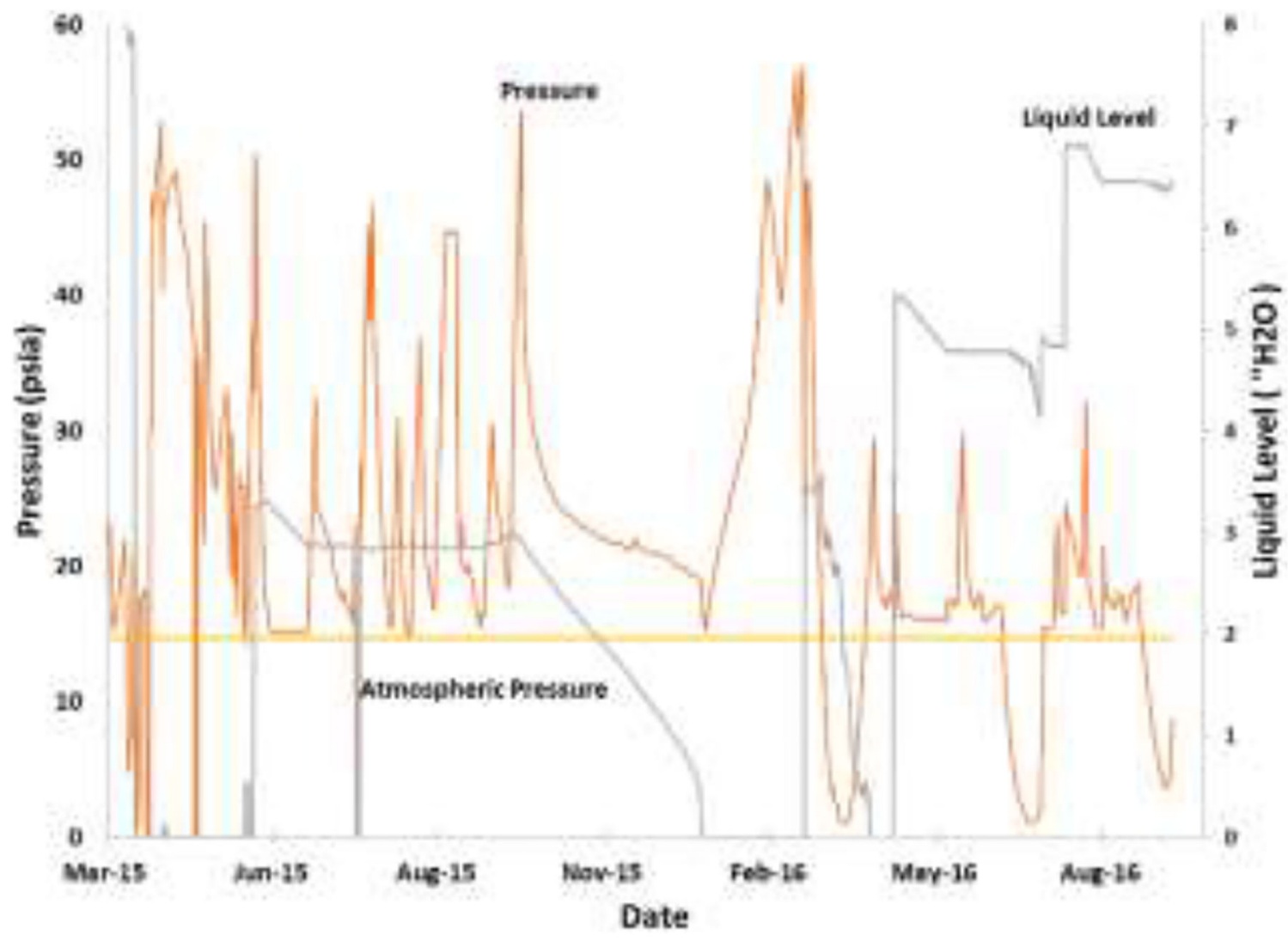

Figure 2.

GODU-LH2 Testing Timeline 


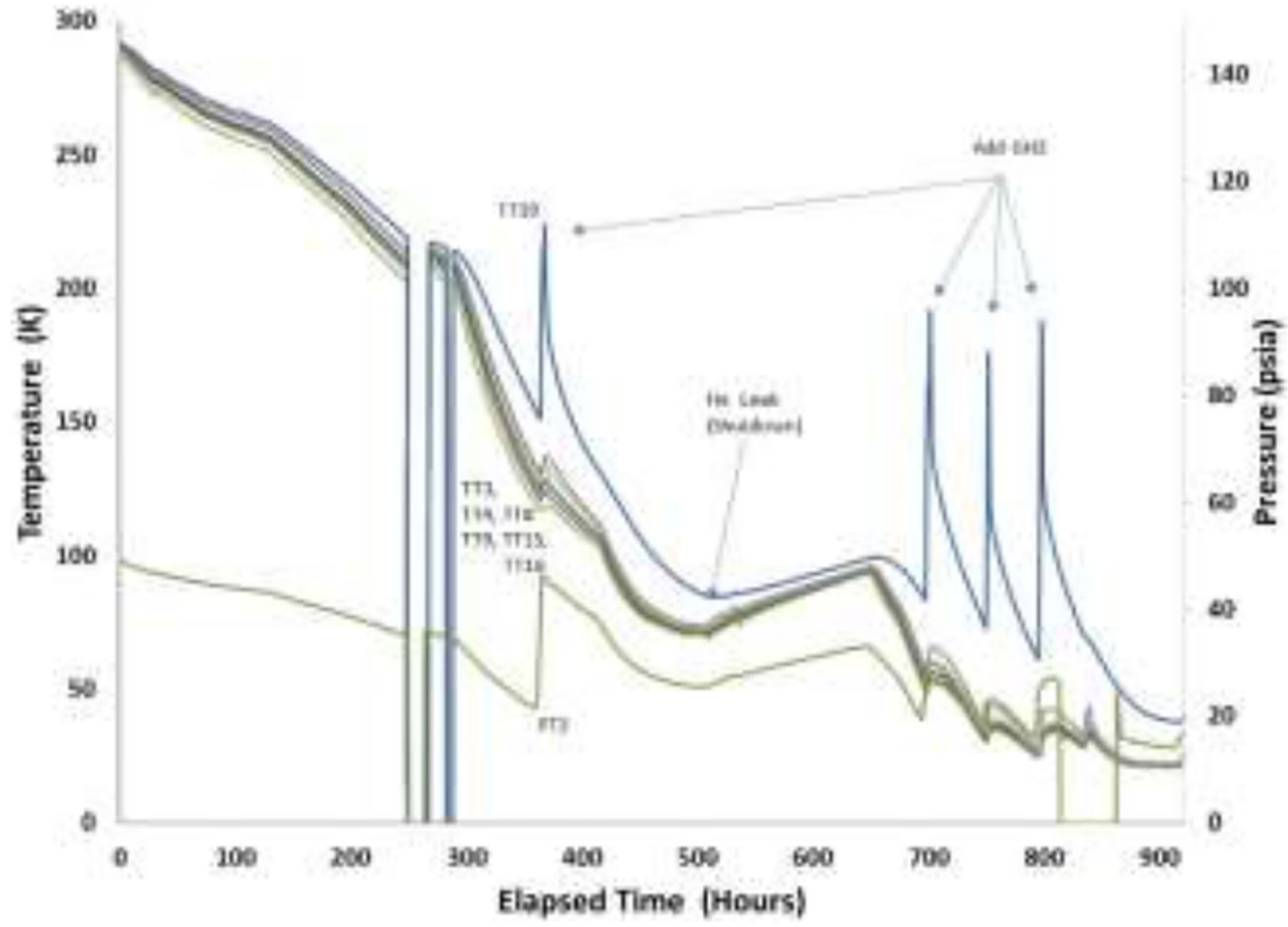

Figure 3.

IRAS Temperature and Pressure during chilldown 


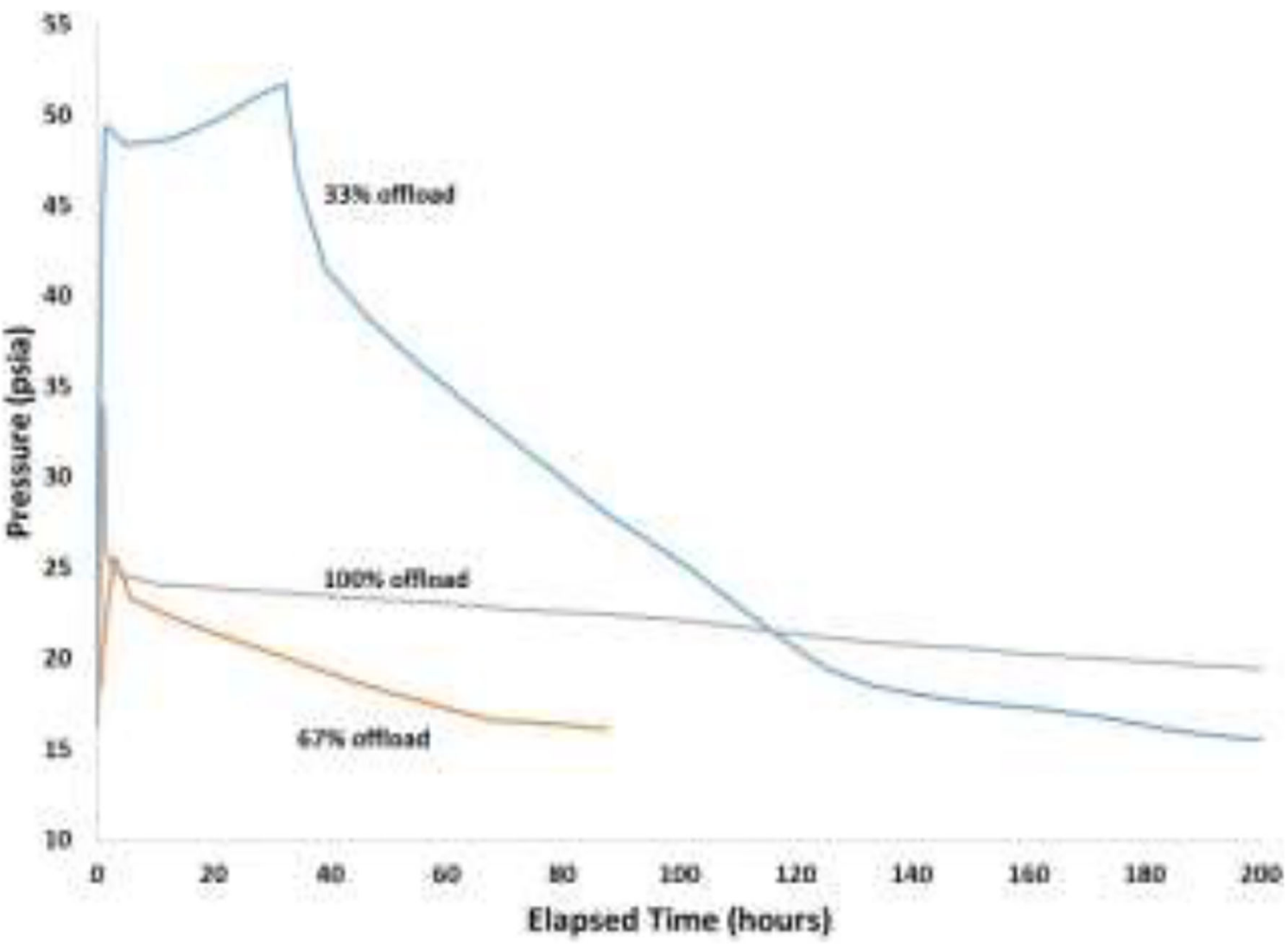

Figure 4.

IRAS Tank Pressure during tanker offload operations 


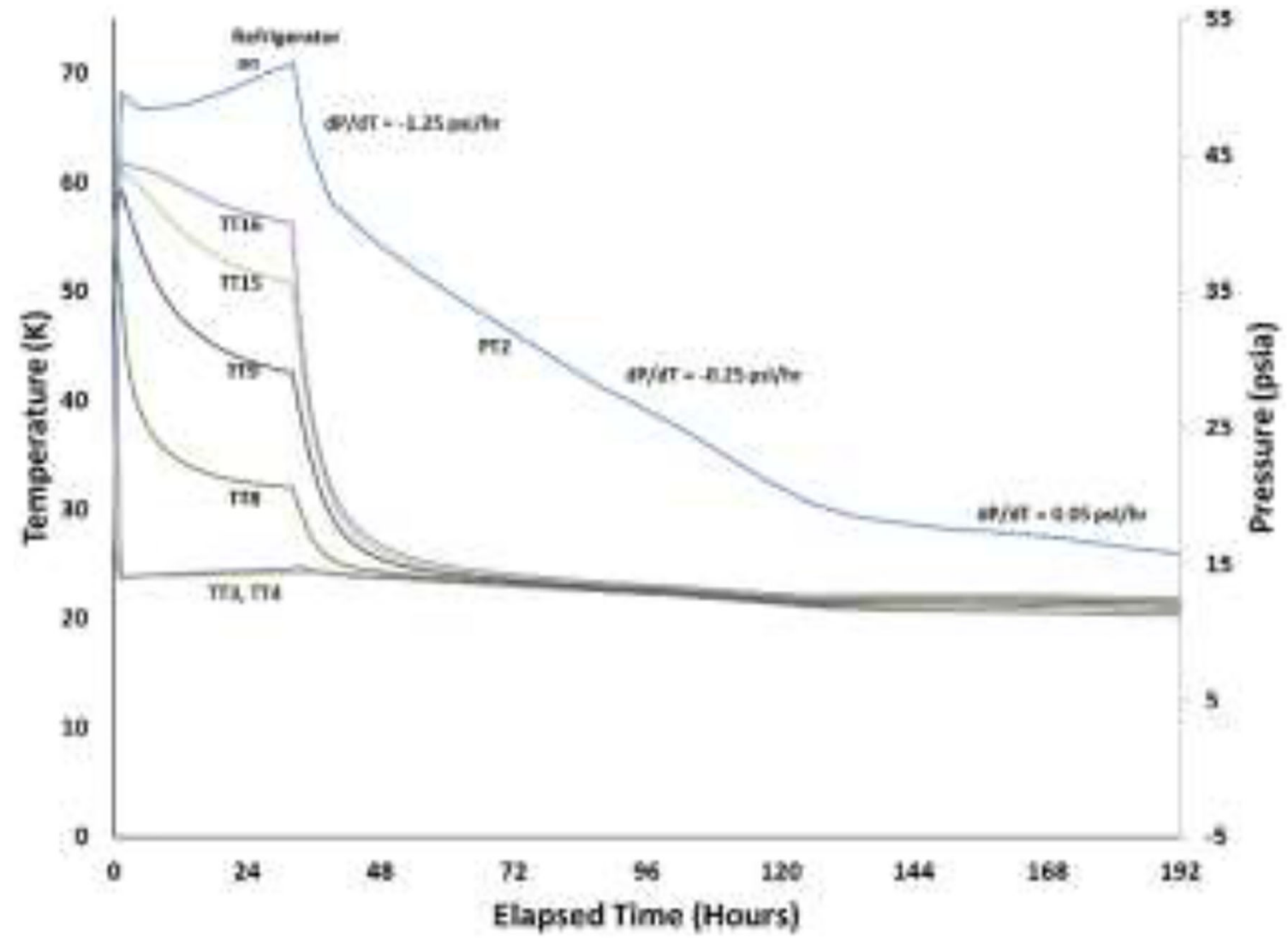

Figure 5.

Pressure and center rake temp during $33 \%$ offload 


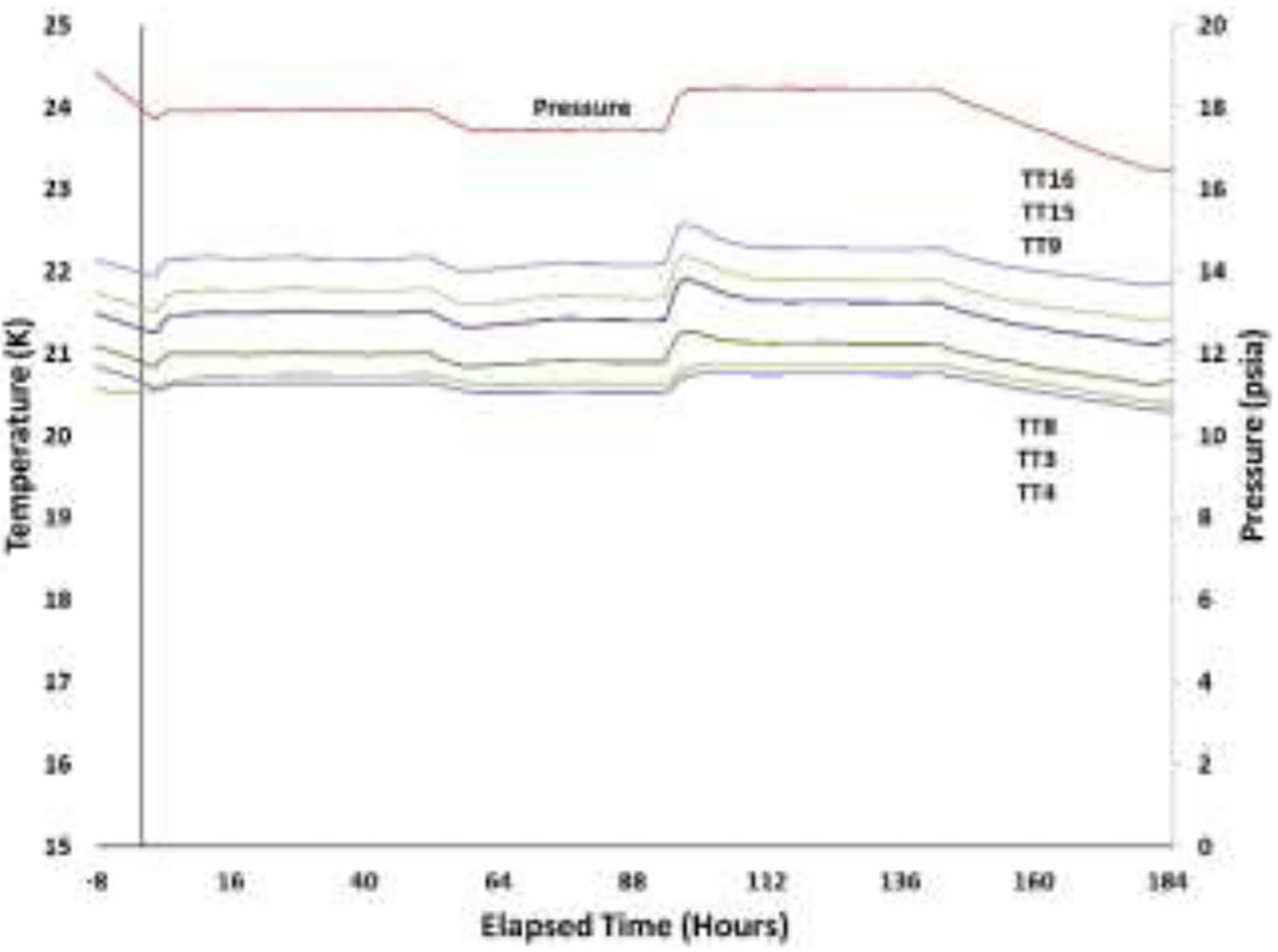

Figure 6.

ZBO Pressure Control Test at 33\% fill level 


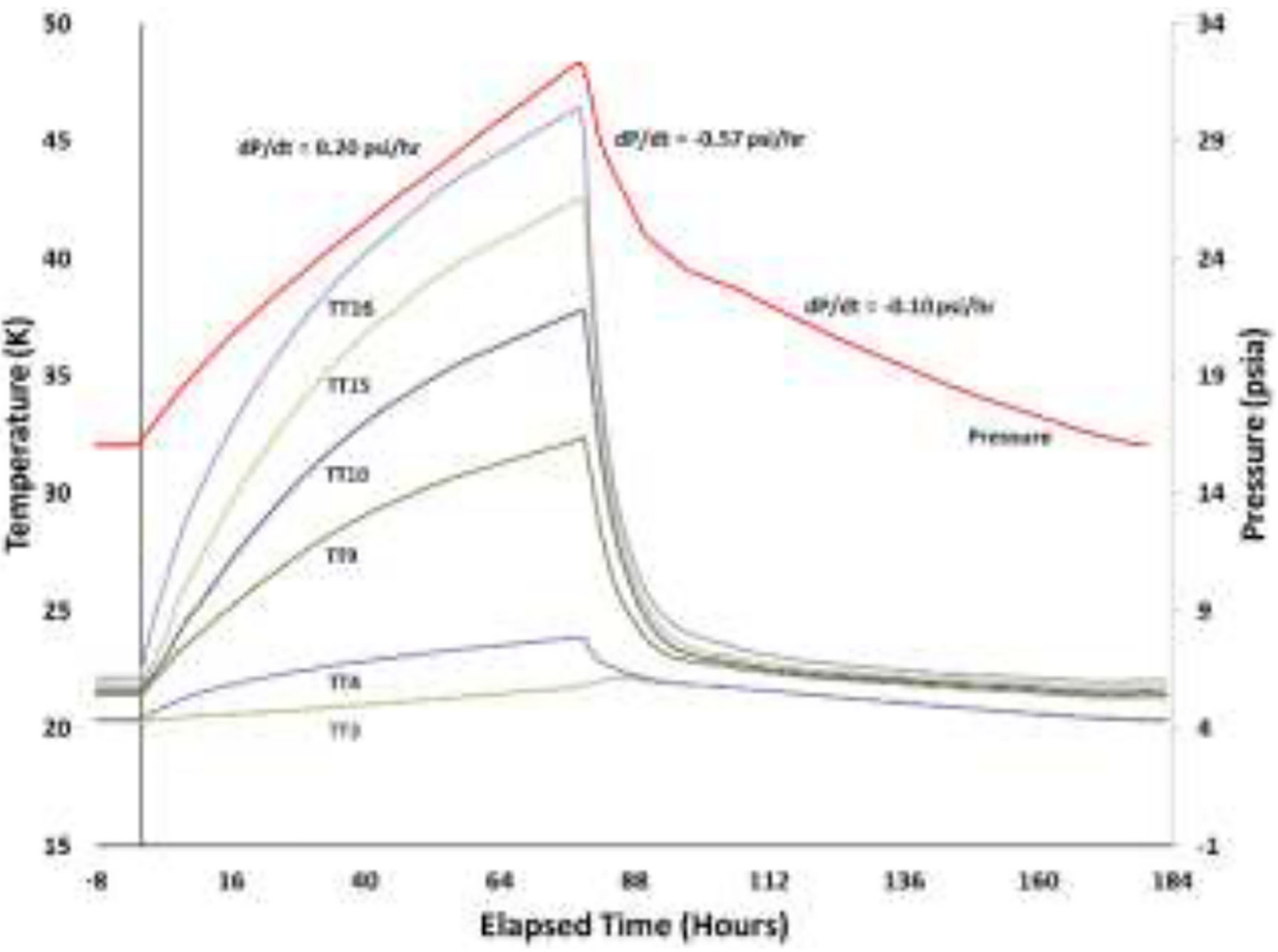

Figure 7.

ZBO Duty Cycle Test at 33\% fill level 


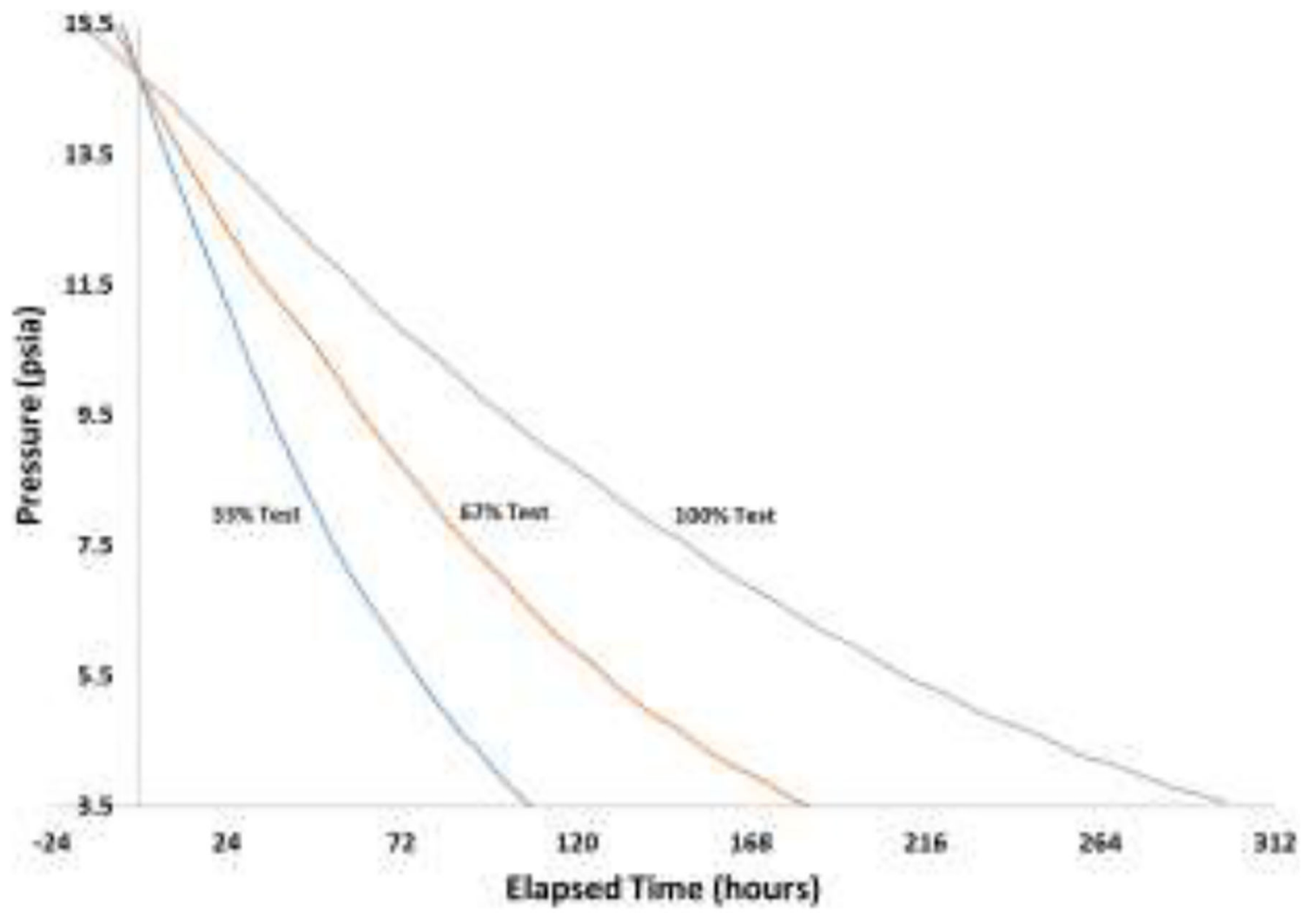

Figure 8.

Tank Pressure during densification testing 


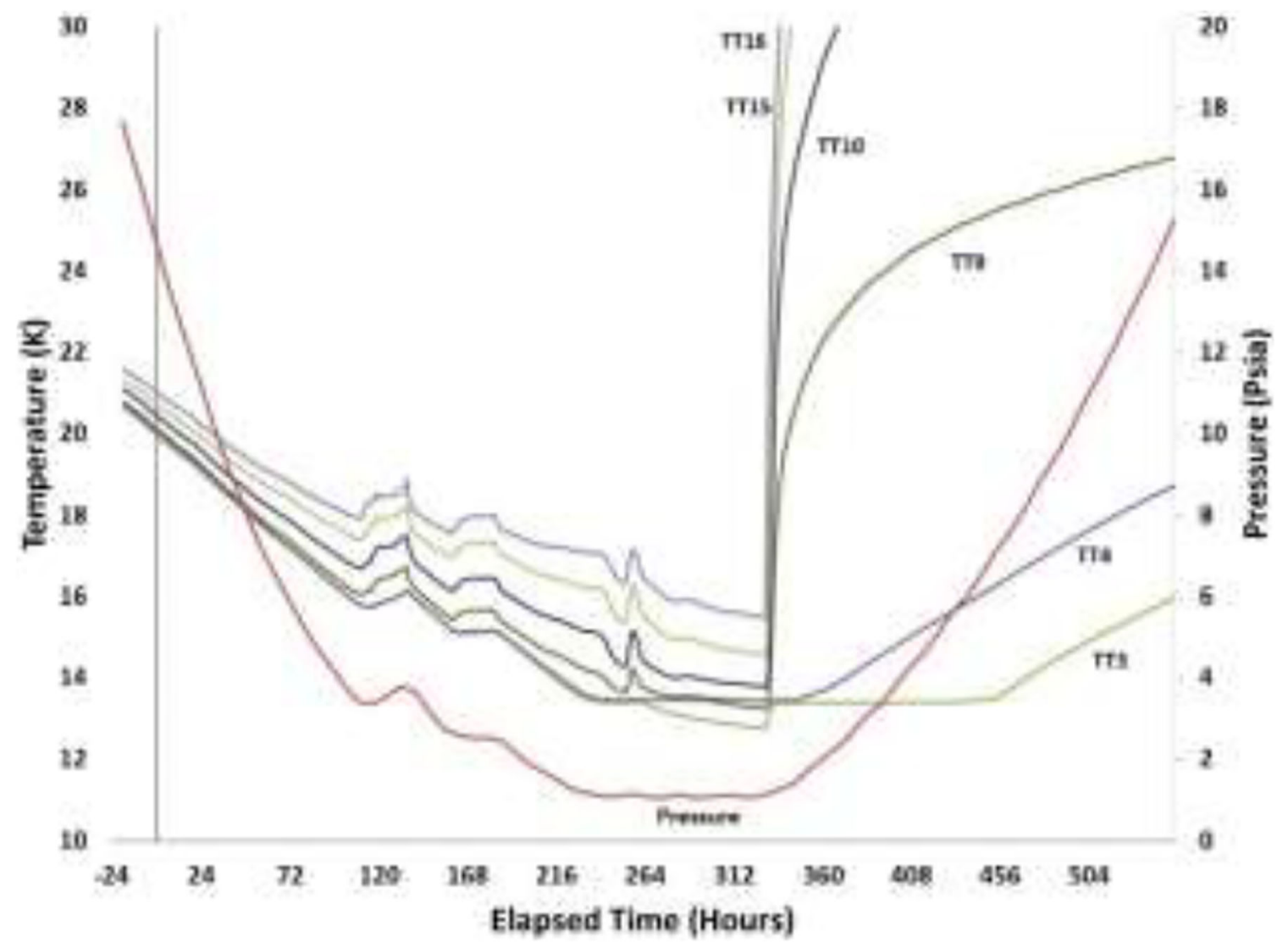

Figure 9.

Pressure and temperature - $33 \%$ densification testing 


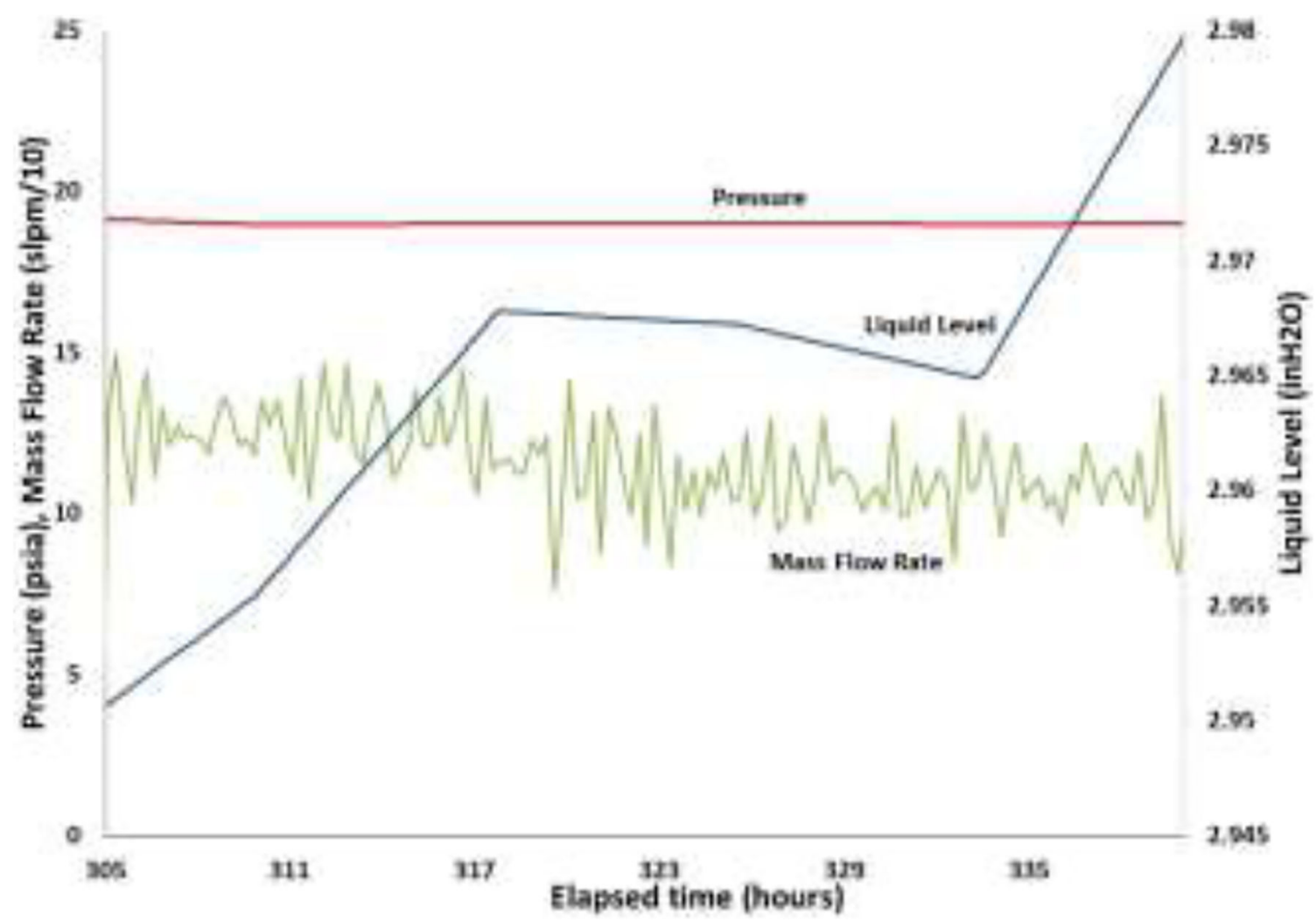

Figure 10.

Liquefaction testing at the $33 \%$ fill level 
Table 1.

Individual testing dates

\begin{tabular}{|l|r|r|}
\hline \multicolumn{1}{|c|}{ Test } & Start Date & End Date \\
\hline Chilldown & $4 / 9 / 2015$ & $5 / 21 / 2015$ \\
\hline Tanker 1 Offload & $5 / 21 / 2015$ & $5 / 29 / 2015$ \\
\hline Tanker 2 Offload & $5 / 3 / 2016$ & $5 / 6 / 2016$ \\
\hline Tanker 3 Offload & $8 / 3 / 2016$ & $8 / 12 / 2016$ \\
\hline $33 \%$ Boil Off & $5 / 29 / 2015$ & $6 / 19 / 2015$ \\
\hline $66 \%$ Boil Off & $5 / 6 / 2016$ & $5 / 31 / 2016$ \\
\hline $100 \%$ Boil Off & $8 / 14 / 2016$ & $8 / 24 / 2016$ \\
\hline $33 \%$ ZBO (Press Control) & $4 / 25 / 2016$ & $5 / 3 / 2016$ \\
\hline $66 \%$ ZBO (Press Control) & $6 / 12 / 2016$ & $6 / 21 / 2016$ \\
\hline $100 \%$ ZBO (Press Control) & $8 / 25 / 2016$ & $9 / 6 / 2016$ \\
\hline $33 \%$ ZBO (Temp Control) & $6 / 23 / 2015$ & $7 / 13 / 2015$ \\
\hline $66 \%$ ZBO (Temp Control) & $6 / 21 / 2016$ & $9 / 29 / 2016$ \\
\hline $100 \%$ ZBO (Temp Control) & $9 / 6 / 2016$ & $9 / 12 / 2016$ \\
\hline $33 \%$ ZBO (Duty Cycle) & $8 / 4 / 2015$ & $8 / 11 / 2015$ \\
\hline $66 \%$ ZBO (Temp Control) & $6 / 5 / 2016$ & $6 / 13 / 2016$ \\
\hline $100 \%$ ZBO (Temp Control) & $8 / 12 / 2016$ & $8 / 16 / 2016$ \\
\hline $33 \%$ Densification & $3 / 24 / 2016$ & $4 / 21 / 2016$ \\
\hline $66 \%$ Densification & $6 / 29 / 2016$ & $7 / 23 / 2016$ \\
\hline $100 \%$ Densification & $9 / 12 / 2016$ & $10 / 5 / 2016$ \\
\hline $0 \%$ Liquefaction & $4 / 9 / 2015$ & $5 / 21 / 2015$ \\
\hline $33 \%$ Liquefaction & $9 / 23 / 2015$ & $10 / 8 / 2015$ \\
\hline $66 \%$ Liquefaction & $7 / 22 / 2016$ & $8 / 2 / 2016$ \\
\hline
\end{tabular}

